\title{
Pharmacokinetics-Driven Evaluation of the Antioxidant Activity of Curcuminoids and Their Major Reduced Metabolites-A Medicinal Chemistry Approach
}

\author{
Gábor Girst ${ }^{1}$, Sándor B. Ötvös ${ }^{2,3}$ (D) Ferenc Fülöp ${ }^{2}$, György T. Balogh ${ }^{4,5, *}$ and Attila Hunyadi $1,6, *$ (D) \\ 1 Institute of Pharmacognosy, Interdisciplinary Centre of Excellence, University of Szeged, \\ H-6720 Szeged, Hungary; girst.gabor@pharmacognosy.hu \\ 2 Institute of Pharmaceutical Chemistry, University of Szeged, H-6720 Szeged, Hungary; \\ sandor.oetvoes@uni-graz.at (S.B.Ö.); fulop.ferenc@szte.hu (F.F.) \\ 3 Institute of Chemistry, University of Graz, NAWI Graz, Heinrichstrasse 28, A-8010 Graz, Austria \\ 4 Department of Chemical and Environmental Process Engineering, Budapest University of Technology and \\ Economics, H-1111 Budapest, Hungary \\ 5 Department of Pharmacodynamics and Biopharmacy, University of Szeged, H-6720 Szeged, Hungary \\ 6 Interdisciplinary Centre of Natural Products, University of Szeged, H-6720 Szeged, Hungary \\ * Correspondence: balogh.gyorgy@vbk.bme.hu (G.T.B.); hunyadi.a@pharmacognosy.hu (A.H.); \\ Tel.: +36-1463-2174 (G.T.B.); +36-6254-6456 (A.H.)
}

Citation: Girst, G.; Ötvös, S.B.; Fülöp, F.; Balogh, G.T.; Hunyadi, A. Pharmacokinetics-Driven Evaluation of the Antioxidant Activity of Curcuminoids and Their Major Reduced Metabolites-A Medicinal Chemistry Approach. Molecules 2021, 26, 3542. https://doi.org/10.3390/ molecules 26123542

Academic Editors: Bruno Botta, Cinzia Ingallina, Andrea Calcaterra and Deborah Quaglio

Received: 30 April 2021

Accepted: 2 June 2021

Published: 10 June 2021

Publisher's Note: MDPI stays neutral with regard to jurisdictional claims in published maps and institutional affiliations.

Copyright: (C) 2021 by the authors. Licensee MDPI, Basel, Switzerland. This article is an open access article distributed under the terms and conditions of the Creative Commons Attribution (CC BY) license (https:// creativecommons.org/licenses/by/ $4.0 /)$.

\begin{abstract}
Curcuminoids are the main bioactive components of the well-known Asian spice and traditional medicine turmeric. Curcuminoids have poor chemical stability and bioavailability; in vivo they are rapidly metabolized to a set of bioreduced derivatives and/or glucuronide and sulfate conjugates. The reduced curcuminoid metabolites were also reported to exert various bioactivities in vitro and in vivo. In this work, we aimed to perform a comparative evaluation of curcuminoids and their hydrogenated metabolites from a medicinal chemistry point of view, by determining a set of key pharmacokinetic parameters and evaluating antioxidant potential in relation to such properties.Reduced metabolites were prepared from curcumin and demethoxycurcumin through continuous-flow hydrogenation. As selected pharmacokinetic parameters, kinetic solubility, chemical stability, metabolic stability in human liver microsomes, and parallel artificial membrane permeability assay (PAMPA)-based gastrointestinal and blood-brain barrier permeability were determined. Experimentally determined $\log P$ for hydrocurcumins in octanol-water and toluene-water systems provided valuable data on the tendency for intramolecular hydrogen bonding by these compounds. Drug likeness of the compounds were further evaluated by a in silico calculations. Antioxidant properties in diphenyl-2-picrylhydrazyl (DPPH) radical scavenging and oxygen radical absorbance capacity (ORAC) assays were comparatively evaluated through the determination of ligand lipophilic efficiency (LLE). Our results showed dramatically increased water solubility and chemical stability for the reduced metabolites as compared to their corresponding parent compound. Hexahydrocurcumin was found the best candidate for drug development based on a complex pharmacokinetical comparison and high LLE values for its antioxidant properties. Development of tetrahydrocurcumin and tetrahydro-demethoxycurcumin would be limited by their very poor metabolic stability, therefore such an effort would rely on formulations bypassing first-pass metabolism.
\end{abstract}

Keywords: curcumin metabolite; continuous-flow hydrogenation; physicochemical characterization; gastrointestinal and blood-brain barrier penetration; pharmacokinetics; metabolism

\section{Introduction}

Curcumin, and its analogs (demethoxycurcumin: DMC, and bisdemethoxycurcumin) can be found in many species from the ginger family (Zingiberaceae) such as in turmeric (Curcuma longa), wild turmeric (Curcuma aromatica) and Javanese turmeric (Curcuma xanthorrhiza). Curcumin is the main bioactive compound of the widely spread "golden spice", 
turmeric, which has been used in traditional Chinese and Ayurvedic medicine for centuries [1]. Natural product research in general has been experiencing a new renaissance recently, which is no wonder considering the high proportion of natural product-originated or -inspired compounds among approved drugs [2]. Curcumin is one of the most studied natural products, with well over 2000 hits for publications on PubMed only for 2020. It was reported to exert a plethora of promising bioactivities in vitro and in vivo, including antiinflammatory [3], antimetastatic [4,5], antiangiogenic [6], antitumor and anti-mutagenic [7], chemo-preventive [8], neuroprotective [9], etc. Its popularity is also shown by the several currently ongoing clinical trials on curcumin, even though it is now recognized as a pan-assay interference-substance (PAINS). This is because of its promiscuous action in a wide variety of in vitro bioassays, giving many false "hits" through non-specific binding to proteins due to its reactivity or interfering with readouts due to its spectroscopic properties $[10,11]$. Because of this, curcumin itself is not a drug-like compound.

Another major issue about the use of curcumin as a potential therapeutic is that it has poor pharmacokinetic properties, low bioavailability and chemical stability, and a rapid metabolism. It was reported that its human consumption is safe in up to $12 \mathrm{~g} /$ day amounts, but its absorption is really poor [12]. Because of curcumin's reactive structure the absorbed amount has a high potential to be metabolized, which was extensively studied in human liver microsomes. In phase I metabolism, the double bonds of curcumin are saturated primarily by the alcohol dehydrogenase route [13]. It is important to stress that a partial or full saturation of the alkyl chain of curcumin eliminates its PAINS properties, therefore these reduced metabolites do not anymore fall into this problematic category of compounds. In Phase II processes the phenolic moiety of curcumin and its reduced derivatives are rapidly conjugated to glucuronides and sulphates.

Some of the main metabolites of curcumin are tetrahydrocurcumin $(4 \mathrm{HC})$, hexahydrocurcumin $(6 \mathrm{HC})$ and octahydrocurcumin $(8 \mathrm{HC})$. These compounds are formed by reductive transformation in human Phase I metabolic route, however that is not the only biotransformation pathway as they can be identified. The curcuminoids $4 \mathrm{HC}$ and $8 \mathrm{HC}$ have been found in Curcuma longa, in the rhizomes and in the leaves, respectively, and $6 \mathrm{HC}$ naturally occurs in the rhizomes of Zingiber officinale [14-16]. Synthetically the easiest way to produce them is by the catalytic hydrogenation of curcumin. In traditional batch reaction, using Palladium on activated carbon as catalyst, all three can be synthesized, and various yields had been reported, ranging from 14 to $68 \%$ for $4 \mathrm{HC}, 9$ to $20 \%$ for $6 \mathrm{HC}$ and 0 to $15 \%$ for $8 \mathrm{HC}$ [17-19]. Using autoclaves at high pressure $8 \mathrm{HC}$ can be produced with as high as $92 \%$ yield [20], and it is also synthesizable from $4 \mathrm{HC}$, with $74 \%$ yield using sodium tetrahydroborate as reagent [21].

Continuous flow hydrogenation typically has many advantages compared to the traditional batch hydrogenation in terms of safety, optimization speed of reaction conditions, reaction efficiency/space-time yields (STY), and residence time/reaction rates. The necessary explosive hydrogen gas is generated in situ and elevated pressure can also be easily provided. Also, the reaction conditions are more controllable, and in most cases this method shows better selectivity [22].

The continuous flow (CF) hydrogenation of curcumin is not quite explored. So far only two articles can be found where the reduction took place under CF conditions. Wagner et al. [23] in 2013 developed an educational laboratory experiment where students use the H-cube continuous flow hydrogenation reactor to prepare $4 \mathrm{HC}$ from curcumin. It is a visible reaction as the bright yellow solution of curcumin turns colorless upon saturation. In the supplementary info, they state that the catalytic reaction in this way gives $92-100 \%$ yield compared to the $60 \%$ achieved in a batch reaction. They used $10 \% \mathrm{Pd} / \mathrm{C}$ as catalyst, and ethanol-ethyl acetate $(1: 1, v / v)$ as solvent at $60^{\circ} \mathrm{C}$ with a flow rate of $1 \mathrm{~mL} / \mathrm{min}$. Batie et al. [24] in 2013 also used an H-cube to reduce the double bonds of a halogenatedcurcumin derivative to tetrahydrohalogenated curcumin with $49 \%$ yield. In these articles they did not mention anything about why the described conditions were chosen. 
There are several in vitro and in vivo experimental evidences that these hydrocurcumin derivatives exhibit similar or even better bioactivity than curcumin such as antioxidant [25], anti-inflammatory [26], antitumor [27] and cardiovascular protective properties [28]. $4 \mathrm{HC}$ and $8 \mathrm{HC}$ have better hepatoprotective effect than curcumin against acetaminophen-induced liver injury and possess superior anti-inflammatory effects in vivo through suppression of TAK1-NF-KB pathway [29-31].

The antioxidant activity of the three main reduced derivatives $(4 \mathrm{HC}, 6 \mathrm{HC}, 8 \mathrm{HC})$ have been thoroughly investigated by Somparn et al., and they concluded that hydrogenated curcumins show better DPPH-scavenging activity and are stronger antioxidants against lipid peroxidation and red blood cell hemolysis [25].

As a part of the preclinical evaluation, extensive characterization of the in silico/in vitro physicochemical and ADME properties is an effective tool to decrease a relative high attrition of active compounds in early stage drug discovery. This approach is widely used for primary screening and preclinical candidate selection, in which the main parameters are kinetic solubility, chemical stability, acid/base properties $\left(\mathrm{p} K_{a}\right)$, lipophilicity $(\log P / D)$, in vitro gastrointestinal and CNS-specific permeability $\left(\mathrm{P}_{\mathrm{e}}, \mathrm{P}_{\text {app }}\right)$ [32] and liver microsomal study focusing on cytochrome P450-mediated metabolic stability $\left(\mathrm{Cl}_{\text {int }}, \mathrm{t}_{1 / 2}\right)[33,34]$.

In the present work, our aim was to further investigate the possibility of the hydrogenation of curcumin in continuous flow reactor, and to see how changing the basic reaction conditions could influence the selectivity of catalytic reduction. Furthermore, we aimed to get more information about the in silico and in vitro physicochemical and pharmacokinetic characteristics of the reduced curcumin metabolites, and to evaluate their antioxidant potential in relation to those properties.

\section{Results and Discussions}

\subsection{Continuous-Flow Hydrogenation of Curcumin}

For the hydrogenation of curcumin, we tried several reaction conditions utilizing the $\mathrm{H}$-cube, including concentration, solvent, pressure, temperature, and flow rate. Yields and space time yields (STY) for the hydrogenated metabolites $4 \mathrm{HC}, 6 \mathrm{HC}$ and $8 \mathrm{HC}$ are shown in Table 1 for each tested condition. Structures of the compounds, along with DMC and its reduced derivatives also studied in this work, are shown in Figure 1.

Table 1. Reaction conditions of the continuous flow hydrogenation of curcumin, and yields achieved for tetra-, hexa-, and octahydrocurcumin (DMC, 4HC, $6 \mathrm{HC}$ and $8 \mathrm{HC}$ respectively). p: pressure set on the instrument, EtOAc: ethyl acetate, T: temperature, STY: space time yield.

\begin{tabular}{|c|c|c|c|c|c|c|c|c|c|c|}
\hline \multirow{2}{*}{$c(\mathrm{mg} / \mathrm{mL})$} & \multirow{2}{*}{ Solvent } & \multirow{2}{*}{$\underset{\text { (bar) }}{p}$} & \multirow{2}{*}{$\begin{array}{c}\mathrm{T} \\
\left({ }^{\circ} \mathrm{C}\right)\end{array}$} & \multirow{2}{*}{$\begin{array}{c}\text { Flow Rate } \\
\text { (ml/min) }\end{array}$} & \multicolumn{3}{|c|}{ Yields (\%) \# } & \multicolumn{3}{|c|}{$\mathrm{STY}(\mathrm{mol} / \mathrm{L} / \mathrm{h}){ }^{\#}$} \\
\hline & & & & & $4 \mathrm{HC}$ & $6 \mathrm{HC}$ & $8 \mathrm{HC}$ & $4 \mathrm{HC}$ & $6 \mathrm{HC}$ & $8 \mathrm{HC}$ \\
\hline 2 & $\mathrm{MeOH}$ & 10 & RT & 1 & 36.7 & 12.5 & 11.7 & 0.53 & 0.18 & 0.17 \\
\hline 2 & $\mathrm{MeOH}$ & 40 & $\mathrm{RT}$ & 1 & 44.1 & 10.7 & 8.5 & 0.64 & 0.15 & 0.12 \\
\hline 2 & $\mathrm{MeOH}$ & 80 & RT & 1 & 51.9 & 9.4 & 6.2 & 0.75 & 0.14 & 0.089 \\
\hline 0.25 & Toluene & 0 & RT & 1 & 37.6 & 7.9 & 0.0 & 0.068 & 0.014 & n.a. \\
\hline 0.25 & Toluene & 80 & RT & 1 & 38.2 & 14.2 & 1.2 & 0.069 & 0.026 & 0.002 \\
\hline 0.25 & Toluene & 80 & 80 & 1 & 42.8 & 18.0 & 2.2 & 0.077 & 0.032 & 0.004 \\
\hline 2 & EtOAc & 0 & 25 & 0.5 & 56.4 & 12.1 & 7.6 & 0.41 & 0.087 & 0.055 \\
\hline 15 & $\begin{array}{c}\text { EtOAc:EtOH } \\
(1: 1, v / v)\end{array}$ & 10 & 60 & 1 & 58.4 & 11.0 & 2.8 & 6.31 & 1.19 & 0.30 \\
\hline
\end{tabular}

\# Determined by HPLC on the crude product mixtures by single-point experiments. 
<smiles>[R]Oc1cc(/C=C/C(=O)/C=C(O)/C=C/c2ccc(O)c(OC)c2)ccc1O</smiles><smiles>COc1cc(CCC(=O)CC(O)CCc2ccc(O)c(OC)c2)ccc1O</smiles>

$$
\begin{array}{ll}
\text { Curcumin: } & \mathrm{R}=\mathrm{OCH} \\
\text { DMC: } \quad \mathrm{R}=\mathrm{H}
\end{array}
$$<smiles>[R]Oc1ccc(CCC(=O)/C=C(/O)CCc2ccc(O)c(OC)c2)cc1[R]</smiles><smiles>[R]Oc1ccc(CCC(O)CC(O)CCc2ccc(O)c(OC)c2)cc1[R]</smiles>

Figure 1. Structures of the curcuminoids and their reduced derivatives studied in this work. DMC: demethoxycurcumin, 4HC: tetrahydrocurcumin, 4HDC: tetrahydro-demethoxycurcumin, $6 \mathrm{HC}$ : hexahydrocurcumin, $8 \mathrm{HC}$ : octahydrocurcumin, 8HDC: octahydro-demethoxycurcumin.

In the case of methanol as solvent, increasing the pressure led to an increased selectivity towards tetrahydrocurcumin $(4 \mathrm{HC})$. When using a less polar solvent, toluene, in which the solubility of curcumin is worse, at room temperature $8 \mathrm{HC}$ was barely formed, which could be explained by the shifted keto-enol tautomer equilibrium. Increasing the residence time by lowering the flow rate does not improve the selectivity towards the more saturated compounds. Increasing the concentration of the substrate seems to change the selectivity towards $4 \mathrm{HC}$.

With these results we have a better understanding about how the basic parameters influence the selectivity of the hydrogenation of curcumin, using continuous flow hydrogenation reactor. This method might not have the best achievable selectivity, it is a good and safer way to produce hydrogenated curcumin metabolites.

\subsection{In Silico and Experimental Physicochemical and Pharmacokinetic Characterization}

Because curcumin and its reduced metabolites cover a narrow chemical space, a multiparametric characterization of the compounds is of high relevance. This was performed using in silico and experimental ADME-related parameters (Tables 2 and 3). Comparing the predicted and measured aqueous kinetic solubility data, it was found that the solubility of the hydrocurcumins is much higher than that of curcumin and its demethoxy analog (DMC). Furthermore, both datasets indicate the enhanced solubility of 6HC. The metabolites $(4 \mathrm{H}(\mathrm{D}) \mathrm{C}-6 \mathrm{H}(\mathrm{D}) \mathrm{C})$ did not show any chemical degradation in PBS (pH 7.4) medium at $37^{\circ} \mathrm{C}$ after $2 \mathrm{~h}$, while relatively short shelf-life was found for curcumin and DMC respectively. This is well in line with previous studies on the chemical instability of curcumin under such conditions; as reported by Wang et al., curcumin suffers a rapid oxidative fragmentation in cell culture medium, which should play a significant role in the pharmacological promiscuity of this compound [35]. Interestingly, human liver microsomes metabolize $4 \mathrm{HC}$ and $4 \mathrm{HDC}$ even faster than curcumin, showing an order of intrinsic clearance $\left(\mathrm{Cl}^{\prime}\right.$ int $)$ as $4 \mathrm{HC} \approx 4 \mathrm{HDC}>\mathrm{DMC}>$ curcumin $>6 \mathrm{HC}>>8 \mathrm{HC}>8 \mathrm{HDC}$. A semi-qualitative investigation of microsomal transformation was also performed by characteristic mass change of curcumin and its analogs using LC-MS data (see Supporting Information, Table S1). Based on the change of $m / z$ values from parent compounds (M) as a starting material and similarity in retention times, the formation of $6 \mathrm{HC}$ as a major metabolite was identified by the reductive metabolism of curcumin $(\mathrm{M}+6)$ and $4 \mathrm{HC}$ $(\mathrm{M}+2)$ and also by the oxidative transformation of $8 \mathrm{HC}(\mathrm{M}-2)$ in the microsomal system. It is also important to note that most of the reductive metabolic routes $(\mathrm{M}+2,+4$ and +6 ) were also identified for both curcumin and the hydrocurcumins. This result is also of interest because previous studies connected the formation of reduced metabolites of 
curcumin to the cytosolic alcohol dehydrogenase [36]. In our case, the formation of reduced metabolites is most likely attributable to the Cytochrome P450 reductase activity from the NADPH-dependent enzyme pool of the microsomal system. Thus, our results also suggest a potential alternative metabolic pathway of curcumin and its reduced derivatives.

Table 2. Experimental physicochemical and in vitro pharmacokinetic profile of curcumin, demethoxycurcumin and their hydrogenated analogues. $\mathrm{P}_{\mathrm{e}}$ : effective permeability, MR: membrane retention. Kinetic solubility, in vitro human microsomal $t_{1 / 2}$ and $P_{e}$, and the MR values of permeability measurements represent mean \pm S.E.M; ${ }^{*} p<0.001$ by one-way ANOVA and Bonferroni post-hoc test as compared to the corresponding parent compound, i.e., curcumin for $4 \mathrm{HC}, 6 \mathrm{HC}$ and $8 \mathrm{HC}$, and DMC for $4 \mathrm{HDC}$ and $8 \mathrm{HDC}, n=3$.

\begin{tabular}{|c|c|c|c|c|c|c|c|}
\hline \multirow[t]{2}{*}{ Compound } & \multirow{2}{*}{$\begin{array}{c}\text { Kinetic } \\
\text { Solubility }^{\mathrm{a}} \\
\qquad(\mu \mathrm{M})\end{array}$} & \multirow{2}{*}{$\begin{array}{l}\text { Chemical } \\
\text { Stability } \\
\text { Shelf-Life } \\
\text { (min) }\end{array}$} & \multirow{2}{*}{$\begin{array}{l}\text { Met.stab. in HLM } \\
t_{1 / 2} \mathrm{Cl}^{\prime}{ }_{\text {int }} \\
(\mathrm{min}) /(\mathrm{mL} / \mathrm{min} / \mathrm{kg})\end{array}$} & \multicolumn{2}{|c|}{$\begin{array}{c}\text { BBB-PAMPA } \\
(\text { PBS pH 6.5 } \rightarrow \text { pH 7.4) }\end{array}$} & \multicolumn{2}{|c|}{$\begin{array}{c}\text { GI-PAMPA } \\
\text { (PBS pH 7.4) }\end{array}$} \\
\hline & & & & $\begin{array}{c}\mathrm{Pe} \\
\left(\cdot 10^{-7} \mathrm{~cm} / \mathrm{s}\right)\end{array}$ & $\begin{array}{l}\text { MR } \\
(\%)\end{array}$ & $\begin{array}{c}\mathrm{Pe} \\
\left(\cdot 10^{-7} \mathrm{~cm} / \mathrm{s}\right)\end{array}$ & $\begin{array}{l}\text { MR } \\
(\%)\end{array}$ \\
\hline Curcumin & $3.1 \pm 0.1$ & $29.7 \pm 0.6$ & $70.5 \pm 5.1 / 4.5 \pm 0.3$ & $\mathrm{NM}^{\mathrm{d}}$ & $96.7 \pm 0.4$ & $5.0 \pm 0.4$ & $90.6 \pm 0.3$ \\
\hline DMC & $5.7 \pm 0.9$ & $22.1 \pm 0.2$ & $37.8 \pm 0.9 / 8.3 \pm 0.2$ & $\mathrm{NM}^{\mathrm{d}}$ & $98.3 \pm 0.1$ & $10.6 \pm 0.6$ & $85.6 \pm 0.5$ \\
\hline $4 \mathrm{HC}$ & $70.3 \pm 0.2 *$ & Stable \# & $4.34 \pm 0.01 / 71.8 \pm 0.1 *$ & $31.3 \pm 1.1$ & $34.4 \pm 0.6 *$ & $30.3 \pm 1.3 *$ & $13.3 \pm 0.4$ * \\
\hline $4 \mathrm{HDC}$ & $69.5 \pm 3.1 *$ & Stable $\#$ & $4.33 \pm 0.02 / 72.0 \pm 0.4$ * & $20.7 \pm 0.5$ & $40.9 \pm 1.5 *$ & $20.4 \pm 0.3 *$ & $12.9 \pm 1.6^{*}$ \\
\hline $6 \mathrm{HC}$ & $74.1 \pm 0.3^{*}$ & Stable ${ }^{\#}$ & $94.4 \pm 3,9 / 3.3 \pm 0.2$ & $12.5 \pm 0.1$ & $13.3 \pm 0.5 *$ & $3.7 \pm 0.2 *$ & $5.0 \pm 0.6 *$ \\
\hline $8 \mathrm{HC}$ & $72.9 \pm 0.9 *$ & Stable \# & $231.7 \pm 33.6 / 1.4 \pm 0.2 *$ & $9.7 \pm 0.2$ & $8.9 \pm 1.4 *$ & $2.4 \pm 0.1^{*}$ & $4.4 \pm 0.2 *$ \\
\hline 8HDC & $68.7 \pm 0.7 *$ & Stable $\#$ & $365.1 \pm 57.4 / 0.9 \pm 0.2 *$ & $5.3 \pm 0.7$ & $14.9 \pm 1.9 *$ & $2.2 \pm 0.1 *$ & $1.7 \pm 0.3 *$ \\
\hline
\end{tabular}

a after $2 \mathrm{~h}$, at $37^{\circ} \mathrm{C}$ in PBS, $\mathrm{pH} 7.4{ }^{\mathrm{b}}$ between $0-2 \mathrm{~h}$ at $37^{\circ} \mathrm{C}$ in PBS, $\mathrm{pH} 7.4{ }^{\circ}{ }^{\mathrm{c}}$ Metabolic stability in human liver microsomes (HLM); intrinsic clearance $\left(\mathrm{Cl}^{\prime}{ }_{\text {int }}\right)$ values were calculated from in vitro $t_{1 / 2}$ data in HLM system as described in the Materials and Methods section. ${ }^{d}$ The permeability value could not be measured due to the high membrane retention. \# No chemical change was detected during the evaluation time (4h).

Due to the almost complete GI-specific lipid membrane retention (MR), the gastrointestinal permeability of curcumin and DMC could not be determined, while its reduced metabolites followed the $4 \mathrm{HC}>4 \mathrm{HDC}>6 \mathrm{HC}>8 \mathrm{HC}>8 \mathrm{HDC}$ order from medium to low. A similar situation was identified in the blood-brain barrier-specific lipid permeability assay, i.e., the decreased permeability of curcumin and DMC correlated with their elevated membrane retention. In this case, the BBB permeability order was found as $4 \mathrm{HC}>4 \mathrm{HDC}>\mathrm{DMC}>$ curcumin $>6 \mathrm{HC} \approx 8 \mathrm{HC} \approx 8 \mathrm{HDC}$ (Table 2). A similar order to the experimental data can be identified based on the corresponding predicted values (CNS MPO, logBB, Caco-2 permeability) for the drug absorption property of curcumin and its metabolites. A more detailed overview of lipophilicity (Table 3 ) and permeability (GI-PAMPA, Table 2) data revealed a slightly confusing relationship between hydrocurcumin derivatives. While the kinetic solubility of these compounds, which also affects their PAMPA-based permeability, is nearly identical, unclear positive correlation can be shown between predicted lipophilicity values and $\mathrm{P}_{\mathrm{e}}$ data. Considering the structure of hydrocurcumins, a possible explanation for this phenomenon is the existence of intramolecular hydrogen bonds (IMHB), which improves the ADME properties of drugs, especially their absorption as suggested by several studies [37-39]. To confirm the presence of intramolecular interactions in these compounds, the partition behavior of hydrocurcumins was also investigated in both octanol-water $\left(\log \mathrm{P}_{\text {oct } / \mathrm{w}}\right)$ and toluene-water $\left(\log \mathrm{P}_{\mathrm{tol} / \mathrm{w}}\right)$ systems. It has been shown that the difference between $\log \mathrm{P}$ values obtained in two different biphasic systems $\left(\Delta \log \mathrm{P}_{\mathrm{oct} \_t o l}=\log \mathrm{P}_{\mathrm{o} / \mathrm{w}}-\log \mathrm{P}_{\text {tol } / \mathrm{w}}\right)$ is informative of the solutes IMHB properties [39-41]. Based on previous observations, if the increased lipophilicity and the $\Delta \log \mathrm{P}_{\text {oct_tol }}$ of a compound is close to zero, this indicates the high propensity to form IHBD. Investigating the lipophilic character of three structurally relevant hydrocurcumins in two biphasic systems (Table 4) increased lipophilicity, and lowest $\Delta \log \mathrm{P}_{\text {oct_tol }}$ were identified for $4 \mathrm{HC}$ to suggest highest tendency to IMHB in the set of compounds. The experimental $\log \mathrm{P}_{\mathrm{oct} / \mathrm{w}}$ values of $4 \mathrm{HC}, 6 \mathrm{HC}$ and $8 \mathrm{HC}$ correspond to the order of the predicted $\log \mathrm{P}$ values (Table 3 ), and the $\Delta \log \mathrm{P}_{\text {oct_tol }}$ data explain the order of GI- and BBB-specific permeability of $4 \mathrm{HC}>6 \mathrm{HC}>8 \mathrm{HC}$, which is also supported by the same order of probability of IMHB. 
Table 3. Predicted physicochemical and ADME properties of curcumin and hydrocurcumin analogues (using ACD/Labs Percepta software [42]). Papp: apparent permeability. HBD: number of hydrogen bond donors. CNS MPO: Central Nervous System Multiparameter Optimization introduced by Wager et al. [43].

\begin{tabular}{|c|c|c|c|c|c|c|c|c|}
\hline Compound & $\begin{array}{l}\text { Aqueous } \\
\text { Solubility }^{\text {a }} \\
\text { (mg/mL) }\end{array}$ & $\log P / \log D_{7.4}^{b}$ & $\begin{array}{c}\text { TPSA } \\
\left(\AA^{2}\right)\end{array}$ & HBD & $\begin{array}{l}\text { Strongest } \\
p K_{a, a c i d} b\end{array}$ & $\mathrm{CNS}_{\mathrm{MPO}}^{\mathrm{c}}$ & $\log B B^{b}$ & $\begin{array}{c}\text { Caco-2 } \\
\text { Permeability } \\
P_{\mathrm{app}} \\
\left(10^{-6} \mathrm{~cm} / \mathrm{s}\right)\end{array}$ \\
\hline Curcumin & 0.08 & $2.64 / 2.58$ & 96.2 & 3 & 8.3 & 4.66 & 0.03 & 93 \\
\hline DMC & 0.07 & $2.85 / 2.79$ & 87.0 & 3 & 8.3 & 4.91 & 0.18 & 99 \\
\hline $4 \mathrm{HC}$ & 0.10 & $2.41 / 2.38$ & 96.2 & 3 & 8.7 & 4.49 & 0.01 & 45 \\
\hline $4 \mathrm{HDC}$ & 0.15 & $2.79 / 2.76$ & 87.0 & 3 & 8.7 & 4.66 & 0.21 & 54 \\
\hline $6 \mathrm{HC}$ & 0.92 & $1.76 / 1.76$ & 96.2 & 3 & 10.0 & 4.67 & -0.21 & 28 \\
\hline $8 \mathrm{HC}$ & 0.22 & $2.18 / 2.18$ & 99.4 & 4 & 9.8 & 4.21 & -0.18 & 17 \\
\hline $8 \mathrm{HDC}$ & 0.30 & $2.48 / 2.48$ & 90.2 & 4 & 10.1 & 4.52 & -0.25 & 22 \\
\hline
\end{tabular}

${ }^{\mathrm{a}}$ intrinsic solubility using Drug Profiler unit of Percepta Package. ${ }^{\mathrm{b}}$ Calculated using $\log \mathrm{P}$ (Consensus and $\mathrm{p} K_{a}$ (Classic) settings within Percepta package ${ }^{\mathrm{c}} \mathrm{CNS}$ MPO values were determined using predicted $\log \mathrm{P}, \log \mathrm{D}_{7.4}$, TPSA and HBD values.

Table 4. Lipophilicity of curcumin and hydrocurcumin analogs in two different biphasic (octanolwater: $\log \mathrm{P}_{\mathrm{oct} / \mathrm{w}}$ and toluene-water: $\left.\log \mathrm{P}_{\mathrm{tol} / \mathrm{w}}\right)$ systems. Data represent average \pm S.E.M from five parallel experiments.

\begin{tabular}{cccc}
\hline Compound & $\log \mathbf{P}_{\mathbf{o c t} / \mathbf{w}}$ & $\log \mathbf{P}_{\text {tol } / \mathbf{w}}$ & $\Delta \log \mathbf{P}_{\text {oct_tol }}$ \\
\hline $4 \mathrm{HC}$ & $2.58 \pm 0.07$ & $2.27 \pm 0.05$ & 0.31 \\
$6 \mathrm{HC}$ & $2.15 \pm 0.01$ & $1.69 \pm 0.03$ & 0.46 \\
$8 \mathrm{HC}$ & $2.30 \pm 0.02$ & $1.55 \pm 0.14$ & 0.75 \\
\hline
\end{tabular}

Since in the reduced metabolites the connecting chain does not have any double bonds conjugated with the two aromatic moieties, demethoxylation cannot have an influence on the IMHB probability, therefore DMC and its reduced metabolites must follow the same tendency.

Overall, due to its favorable solubility, chemical stability, optimal liver microsomal stability and moderate permeability property, $6 \mathrm{HC}$ has the best properties among curcumin and its reduced metabolites from a medicinal chemistry point of view. However, due to the increased GI- and BBB-specific penetration of $4 \mathrm{HC}$ and $4 \mathrm{HDC}$, these may also be suitable clinical candidates with a drug delivery strategy that bypasses first-pass metabolism. It is also important to highlight our finding that $6 \mathrm{HC}$ were identified as a recurrent metabolite of both curcumin and its reduced analogs.

\subsection{Antioxidant Activity}

The antioxidant activity of curcumin, demethoxycurcumin and their hydrogenated derivatives have been comparatively investigated using multiple models [25]. To evaluate their in vitro free radical scavenging activity in relation to our pharmacokinetic results, we completed our study by measuring the capacity of these compounds to scavenge diphenyl2-picrylhydrazyl (DPPH) radicals and by determining their oxygen radical absorbance capacity (ORAC); results are compiled in Table 5.

These two methods offer some complementary information due to their reaction mechanisms with small-molecule antioxidants: DPPH may react through single-electron transfer (SET) or hydrogen atom transfer (HAT) mechanism, while the ORAC assay works mainly through HAT [40]. Our results correlate with those published before, i.e., 4HC shows the best activity against DPPH, while the demethoxy derivatives the worst. 
Table 5. Antioxidant activity of hydrocurcumin derivatives. Data represent average \pm S.E.M; ${ }^{*}: p<0.05,{ }^{* * *}: p<0.001$ by one-way ANOVA and Bonferroni post-hoc test as compared to the corresponding parent compound, i.e., curcumin for $4 \mathrm{HC}$,

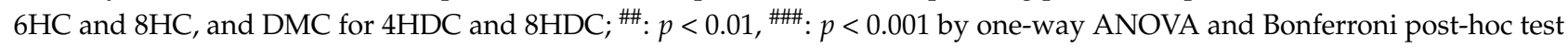
as compared to trolox, $n=6-10$.

\begin{tabular}{|c|c|c|c|c|}
\hline Compound & $\begin{array}{c}\text { DPPH } \\
\mathrm{IC}_{50} \mu \mathrm{M}\end{array}$ & $\operatorname{LLE}^{a}$ (DPPH) & $\begin{array}{l}\text { Antioxidant Capacity (AAPH) } \\
\qquad \mathrm{IC}_{50} \mu \mathrm{M}\end{array}$ & LLE (AAPH) \\
\hline Curcumin & $11.8 \pm 0.1$ & $2.37 \pm 0.004^{\# \# \#}$ & $0.32 \pm 0.10 \# \#$ & $3.96 \pm 0.05^{\# \# \#}$ \\
\hline DMC & $16.8 \pm 0.7$ & $2.09 \pm 0.04^{\# \# \#}$ & $0.49 \pm 0.03^{\# \# \#}$ & $3.63 \pm 0.03^{\# \#}$ \\
\hline $4 \mathrm{HC}$ & $9.8 \pm 0.2$ & $2.60 \pm 0.01$ & $0.43 \pm 0.04$ \#\# & $3.99 \pm 0.05^{\# \#}$ \\
\hline $4 \mathrm{HDC}$ & $14.2 \pm 0.5$ & $2.06 \pm 0.02 \# \# \#$ & $0.41 \pm 0.03^{\# \# \#}$ & $3.60 \pm 0.04^{\# \#}$ \\
\hline $6 \mathrm{HC}$ & $9.9 \pm 0.9$ & 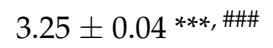 & $0.39 \pm 0.06^{\# \# \#}$ & 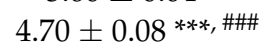 \\
\hline $8 \mathrm{HC}$ & $11.4 \pm 1.0$ & $2.76 \pm 0.04^{* * *}$ & $0.43 \pm 0.11^{\# \# \#}$ & $4.28 \pm 0.11^{*}$ \\
\hline $8 \mathrm{HDC}$ & $33.1 \pm 0.8^{\# \# \#}$ & $2.00 \pm 0.07^{\# \# \#}$ & $0.49 \pm 0.29 \# \#$ & $3.64 \pm 0.12$ \\
\hline Trolox & $5.6 \pm 0.1$ & $2.74 \pm 0.01$ & $2.02 \pm 0.13$ & $3.18 \pm 0.03$ \\
\hline
\end{tabular}

${ }^{\mathrm{a}}$ Ligand-lipophilic efficiency: $\mathrm{LLE}=\mathrm{pIC}_{50}-\log \mathrm{P}_{\text {predicted }}$

Curcumin, DMC and 4HDC showed the best results in the ORAC assay. It is important to mention that such chemical antioxidant assays alone have low in vivo relevance [41]. Nevertheless, they still provide valuable input data to compare the antioxidant potential of related compounds when corrected with a relevant pharmacokinetic property to obtain a related ligand efficiency (LLE) measure that is an approach of major importance in drug discovery [44]. Accordingly, when calculating lipophilic ligand efficiency to both applied free radical scavenging assays, hexahydrocurcumin $(6 \mathrm{HC})$ was found to be by far the best lead among the compounds studied, and the only derivative that was superior to both its parent compound, curcumin, and trolox in both assays according to its LLE value.

\section{Materials and Methods}

\subsection{Synthesis and Chromatographic Purification}

Curcumin ( $\geq 98 \%$ curcuminoid, $\geq 65 \%$ curcumin content) and all other reagents were purchased from Sigma (Merck KGaA, Darmstadt, Germany) and the solvents were obtained from Macron Fine Chemicals (Avantor Performance Materials, Center Valley, PA, USA).

For the purification of curcumin a flash method was selected based on Jayaprakasha et al. [45] using silica ( $40 \mathrm{~g}$ ) and diol ( $30 \mathrm{~g}$ ) columns in series. For this a CombiFlashfi Rf + Lumen apparatus (TELEDYNE Isco, Lincoln, NE, USA) was utilized that was equipped with ELS and diode array detectors.

Using various conditions curcumin was reduced to tetrahydrocurcumin, hexahydrocurcumin and octahydrocurcumin, utilizing an H-cube continuous flow hydrogenation reactor (ThalesNano Inc., Budapest, Hungary). For the analytic evaluation of the products RP-HPLC analysis was selected, using a gradient of acetonitrile and water (from $40 \% \mathrm{MeCN}$ to $80 \%$ in $30 \mathrm{~min}$ ) with a Kinetex Biphenyl $250 \times 4.6 \mathrm{~mm}, 5 \mu \mathrm{m}$ column (Phenomenex Inc., Torrance, CA, USA) with a flow rate of $1 \mathrm{~mL} / \mathrm{min}$, using a dual pump (PU-2080) Jasco HPLC instrument (Jasco International Co. Ltd., Hachioji, Tokyo, Japan) with an MD-2010 Plus PDA detector. For the isolation of the products an Armen Spot Prep II integrated HPLC purification system (Gilson, Middleton, WI, USA) with dual-wavelength detection was applied, operating at 220 and $254 \mathrm{~nm}$. Preparative separations were performed on a Kinetex Biphenyl $250 \times 21.2 \mathrm{~mm}, 5 \mu \mathrm{m}$ column with adequately chosen eluents of acetonitrile-water, and the flow rates were $15 \mathrm{~mL} / \mathrm{min}$.

\subsection{Pharmacokinetic Measurements}

Kinetic solubility was tested with $5 \%(v / v)$ DMSO as cosolvent in phosphate buffered saline (PBS, $0.01 \mathrm{M}$ phosphate buffer $\mathrm{pH} 7.4,0.138 \mathrm{M} \mathrm{NaCl}, 0.0027 \mathrm{M} \mathrm{KCl}$, without $\mathrm{Ca}^{2+}$, $\mathrm{Mg}^{2+}$ ) at room temperature for $2 \mathrm{~h}$. Chemical stability was tested with $10 \%(v / v)$ DMSO as cosolvent in PBS pH 7.4 at $37^{\circ} \mathrm{C}$ for $4 \mathrm{~h}$. Metabolic stability was investigated on human liver microsomes $(1 \mathrm{mg} / \mathrm{mL})$, which were preincubated with $25 \mu \mathrm{M}$ test compounds for $5 \mathrm{~min}$ 
at $37{ }^{\circ} \mathrm{C}$ in $0.1 \mathrm{M}$ Tris- $\mathrm{HCl}$ buffer, $\mathrm{pH} 7.4$ contained $6.67 \mathrm{mM}$ Na-pyrophosphate, $5.56 \mathrm{mM}$ $\mathrm{MgCl}_{2}, 5.56 \mathrm{mM}$ glucose-6-phosfate, $4.63 \mathrm{U} / \mathrm{mL}$ glucose-6-phosphate dehydrogenase. The reaction was initiated by adding preincubated cofactor $\left(37^{\circ} \mathrm{C}, 10 \mathrm{mM}\right.$ NADPH$)$. After 10 , 30 , and $60 \mathrm{~min}$ incubation at $37^{\circ} \mathrm{C}$, the reaction was stopped by adding equal volume of cooled methanol $\left(-20{ }^{\circ} \mathrm{C}\right)$. The samples were centrifuged at $20,000 \mathrm{~g}$ for $5 \mathrm{~min}$. The supernatant and all above described test solutions were analyzed by LC-MS/MS. LC-MS analysis was carried out on an Agilent 1200 liquid chromatography system coupled with an 6410 QQQ-MS (Agilent Technologies, Palo Alto, CA, USA). Analysis was on a Cortecs C18 column $(150 \times 4.6 \mathrm{~mm}, 2.7 \mu \mathrm{m}$, Waters $)$ at $40{ }^{\circ} \mathrm{C}$, with a mobile phase flow rate of $1.45 \mathrm{~mL} / \mathrm{min}$. Composition of eluent A was $0.1 \%(v / v)$ trifluoroacetic acid (TFA) in water ( $\mathrm{pH}$ 1.9). A linear gradient of $0-100 \% \mathrm{~B}$ (acetonitrile $(\mathrm{AcN})$ and water in 95:5 (v/v)) was applied at a range of $0-17 \mathrm{~min}$, then $100 \% \mathrm{~B}$ at $17-22 \mathrm{~min}$. The injection volume was set at $20 \mu \mathrm{L}$ and chromatograms were registered at $220 \pm 4 \mathrm{~nm}$. The MSD operating parameters in ESI positive ionization mode were as follows: scan ion mode $(100-800 \mathrm{~m} / \mathrm{z})$, drying gas temperature $350{ }^{\circ} \mathrm{C}$, nitrogen flow rate $12 \mathrm{~L} / \mathrm{min}$, nebulizer pressure 40 psi, quadrupole temperature $100{ }^{\circ} \mathrm{C}$, capillary voltage $4000 \mathrm{~V}$, fragmentor voltage $135 \mathrm{~V}$.

$\mathrm{BBB}$ and GI permeability was determined by using tissue-specific parallel artificial membrane permeability assay (GI-PAMPA [46], BBB-PAMPA [47]) models. Briefly, a 96-well acceptor plate and a 96-well filter plate were assembled into a sandwich. The hydrophobic filter material of the 96 well filter plate was coated by the mixture of phosphatidylcholine:cholesterol 2:1 (5 $\mu \mathrm{L}, 4 \%(w / v)$ in dodecane: GI-PAMPA) or by porcine brain lipid (PBL) $(5 \mu \mathrm{L}, 2.6 \%(w / v)$ in dodecane:hexane 25:75 $v / v \%$ : BBB-PAMPA). Subsequently, the acceptor wells at the bottom of the sandwich were filled with $300 \mu \mathrm{L}$ of $10 \mathrm{mM}$ PBS solution with 5\% DMSO adjusted to $\mathrm{pH}$ 7.4. The donor wells at the top of the sandwich were hydrated with $150 \mu \mathrm{L}$ of test compound solution. The test compound solutions were prepared in 100 times dilution. Firstly, a $10 \mathrm{mM}$ stock solution was prepared from the corresponding compound in DMSO, then it was diluted with PBS (pH 6.5: GI-PAMPA or $\mathrm{pH} 7.4$ : BBB-PAMPA) to get $5 \%$ mixture followed by filtration through a MultiScreen Solubility filter plate. The resulting sandwich was then incubated at $37^{\circ} \mathrm{C}$ for $4 \mathrm{~h}$. After the incubation, PAMPA sandwich plates were separated and compound concentrations in donor and acceptor solutions were investigated by HPLC-DAD. HPLC analyses were performed using a Shimadzu Prominence Modular HPLC system (Shimadzu Corporation, Kyoto, Japan) on a Kinetex ${ }^{\circledR} 2.6 \mathrm{~mm} \mathrm{C18} 100 \AA$ LC column $(30 \times 3 \mathrm{~mm})$ at $45^{\circ} \mathrm{C}$. Mobile phase flow rate was $1.1 \mathrm{~mL} / \mathrm{min}$ using a gradient of $\mathrm{AcN}$ and $0.1 \%(v / v)$ formic acid in water (from $5 \% \mathrm{AcN}$ to $95 \%$ in $2.5 \mathrm{~min}$ ). Chromatograms were recorded at the wavelength of 200-500 nm, integration was carried out at the $U V_{\max }$ of each compound. The applied injection volume was $6 \mu \mathrm{L}$.

\subsection{Determination of Experimental $\log P$ Values}

Lipophilicity measurements of hydrocurcumins were performed by dissolving the compounds in the organic solvents (octanol and toluene) at $1 \mathrm{mg} / \mathrm{mL}$ concentration and mixing them with water (1:5 and 1:10 ratios, each in five replicates). After $24 \mathrm{~h}$ the concentration of the compounds in the aqueous phase were calculated by using a calibration dilution series measured on RP-HPLC system. The concentration of the organic phase was calculated from the concentration of the aqueous phase.

\subsection{Antioxidant Activity}

\subsubsection{Diphenyl-2-picrylhydrazyl (DPPH)-Assay}

The DPPH free radical scavenging assay was performed based on the method of Fukumoto et al. [48] with some modification. The measurement was performed on a 96well microplate. Microdilution series of the samples $(0.2 \mathrm{mg} / \mathrm{mL}$ stock solution, dissolved in HPLC grade $\mathrm{MeOH}$ ) were made starting with $100 \mu \mathrm{L}$. To each well $100 \mu \mathrm{L}$ of DPPH reagent $(100 \mu \mathrm{M}$ in HPLC grade $\mathrm{MeOH})$ was added to gain the final volume of $200 \mu \mathrm{L}$. The microplates were kept in dark, and the absorbance was measured after 30 min at 
$550 \mathrm{~nm}$ using a FluoStar Optima plate reader (software version 2.20R2, BMG Labtech, Ortenberg, Germany). Methanol was used as blank. The scavenging activity was calculated as Inhibition $(\%)=(\mathrm{A} 0-\mathrm{As}) / \mathrm{A} 0 \times 100$, and $\mathrm{EC}_{50}$ values were calculated by Graph Pad Prism (GraphPad Software, Inc., La Jolla, CA, USA).

\subsubsection{AAPH Assay}

Antioxidant capacity measurement was carried out on 96-well microplates, based on oxygen radical absorbance capacity (ORAC) assay [49]. A $20 \mu \mathrm{L}$ aliquot of the sample (6 dilutions with buffer from $10 \mu \mathrm{g} / \mathrm{mL}$ stock solution dissolved in phosphate buffer, containing $1 \% \mathrm{MeOH}$ ), $120 \mu \mathrm{L}$ of fluorescein (dissolved in phosphate buffer, $\mathrm{pH}=7.4,70 \mathrm{nM}$ final concentration), and $60 \mu \mathrm{L}$ of 2,2'-azobis(2-methylpropionamidine) dihydrochloride (AAPH, dissolved in phosphate buffer, $\mathrm{pH}=7.4,12 \mathrm{mM}$ final concentration) were pipetted into each well. Each measurement was performed twice in duplicates. Each plate contained six dilutions of trolox as the standard, and phosphate buffer as blank. Flourescence (excitation at $485 \mathrm{~nm}$ and emission at $520 \mathrm{~nm}$ ) was measured over a $3 \mathrm{~h}$ period with $1.5-\mathrm{min}$ cycle intervals by a FluoStar Optima plate-reader (BMG Labtech GmbH). The antioxidant capacity was calculated for each concentration with the following formula: antioxidant capacity $=\left(\mathrm{AUC}_{\text {Antioxidant }}-\mathrm{AUC}_{\text {Blank }}\right) / \mathrm{AUC}_{\mathrm{Blank}} \times 100$ where $\mathrm{AUC}$ is the area under curve obtained for the sample and blank assays. Based on the linear correlation between the concentration of the samples and the antioxidant capacity, $\mathrm{IC}_{50}$ values could be obtained, which define the concentration (in $\mu \mathrm{M}$ ) of each compound required to have $50 \%$ antioxidant capacity defined by the previous equation.

\section{Conclusions}

Based on our results, hydrogenated curcumins could potentially be used as novel pharmacotherapeutics. They show better pharmacokinetic properties and higher bioavailability in various relevant models than curcumin. Among the tested compounds, hexahydrocurcumin was found by far the best lead for a possible further development: it had the best kinetic solubility, a good metabolic stability, appropriate GI and BBB penetration properties, and, importantly, the best lipophilic-ligand efficiency as an antioxidant.

Tetrahydrocurcumin and tetrahydrodemethoxycurcumin, however, demonstrated surprisingly low metabolic stability in human liver microsomes, and this was much lower than that of curcumin. Therefore, despite their otherwise good performance concerning some important physicochemical parameters (e.g., showing the best GI and BBB penetration), the applicability of tetrahydrocurcuminoids as possible lead compounds would rely on an appropriate formulation bypassing the first-pass metabolism.

Supplementary Materials: The following are available online. Table S1. LC-MS metabolite fingerprint data of each compound following their incubation with human liver microsomes, Figures S1-S7. ${ }^{1} \mathrm{H}$ NMR spectra of the compounds.

Author Contributions: G.G. performed synthesis, antioxidant assays and $\log P$ determination, and analized related data, S.B.Ö. and F.F. provided access to the $\mathrm{H}$-cube equipment and related scientific background, G.T.B. performed and evaluated all pharmacokinetics-related experiments and in silico predictions, A.H. and G.T.B. conceived and designed the study and supervised the lab work; A.H., G.T.B. and G.G. wrote the manuscript. All authors have read and agreed to the published version of the manuscript.

Funding: This work was supported by the National Research, Development and Innovation Office, Hungary (NKFIH; K-134704), and the Ministry of Human Capacities, Hungary grant 20391-543 3/2018/FEKUSTRAT.

Institutional Review Board Statement: Not applicable.

Informed Consent Statement: Not applicable.

Data Availability Statement: Raw datasets are available from the authors upon request. 
Conflicts of Interest: The authors declare no conflict of interest. The founding sponsors had no role in the design of the study; in the collection, analyses, or interpretation of data; in the writing of the manuscript; or in the decision to publish the results.

Sample Availability: Samples of each compound evaluated in this study are available from the authors.

\section{References}

1. Amalraj, A.; Pius, A.; Gopi, S.; Gopi, S. Biological activities of curcuminoids, other biomolecules from turmeric and their derivatives-A review. J. Tradit. Complement. Med. 2017, 7, 205-233. [CrossRef]

2. Newman, D.J.; Cragg, G.M. Natural Products as Sources of New Drugs over the Nearly Four Decades from 01/1981 to 09/2019. J. Nat. Prod. 2020, 83, 770-803. [CrossRef]

3. Fadus, M.C.; Lau, C.; Bikhchandani, J.; Lynch, H.T. Curcumin: An age-old anti-inflammatory and anti-neoplastic agent. J. Tradit. Complement. Med. 2017, 7, 339-346. [CrossRef]

4. Hu, C.; Li, M.; Guo, T.; Wang, S.; Huang, W.; Yang, K.; Liao, Z.; Wang, J.; Zhang, F.; Wang, H. Anti-metastasis activity of curcumin against breast cancer via the inhibition of stem cell-like properties and EMT. Phytomedicine 2019, 58, 152740. [CrossRef] [PubMed]

5. Menon, L.G.; Kuttan, R.; Kuttan, G. Anti-metastatic activity of curcumin and catechin. Cancer Lett. 1999, 141, 159-165. [CrossRef]

6. Bhandarkar, S.S.; Arbiser, J.L. Curcumin as an Inhibitor of Angiogenesis. In The Molecular Targets and Therapeutic Uses of Curcumin in Health and Disease; Aggarwal, B.B., Surh, Y.-J., Shishodia, S., Eds.; Springer US: Boston, MA, USA, 2007; pp. 185-195. [CrossRef]

7. Shukla, Y.; Arora, A.; Taneja, P. Antimutagenic potential of curcumin on chromosomal aberrations in Wistar rats. Mutat. Res. Genet. Toxicol. Environ. Mutagenesis 2002, 515, 197-202. [CrossRef]

8. Surh, Y.-J.; Chun, K.-S. Cancer Chemopreventive Effects of Curcumin. In The Molecular Targets and Therapeutic Uses of Curcumin in Health and Disease; Aggarwal, B.B., Surh, Y.-J., Shishodia, S., Eds.; Springer US: Boston, MA, USA, 2007; pp. 149-172. [CrossRef]

9. Maiti, P.; Dunbar, G.L. Comparative Neuroprotective Effects of Dietary Curcumin and Solid Lipid Curcumin Particles in Cultured Mouse Neuroblastoma Cells after Exposure to A 342 . Int. J. Alzheimer's Dis. 2017, 2017, 4164872. [CrossRef]

10. Nelson, K.M.; Dahlin, J.L.; Bisson, J.; Graham, J.; Pauli, G.F.; Walters, M.A. The Essential Medicinal Chemistry of Curcumin. J. Med. Chem. 2017, 60, 1620-1637. [CrossRef] [PubMed]

11. Baell, J.; Walters, M.A. Chemistry: Chemical con artists foil drug discovery. Nature 2014, 513, 481-483. [CrossRef]

12. Anand, P.; Kunnumakkara, A.B.; Newman, R.A.; Aggarwal, B.B. Bioavailability of Curcumin: Problems and Promises. Mol. Pharm. 2007, 4, 807-818. [CrossRef]

13. Siviero, A.; Gallo, E.; Maggini, V.; Gori, L.; Mugelli, A.; Firenzuoli, F.; Vannacci, A. Curcumin, a golden spice with a low bioavailability. J. Herb. Med. 2015, 5, 57-70. [CrossRef]

14. Liao, Y.-R.; Leu, Y.-L.; Chan, Y.-Y.; Kuo, P.-C.; Wu, T.-S. Anti-Platelet Aggregation and Vasorelaxing Effects of the Constituents of the Rhizomes of Zingiber officinale. Molecules 2012, 17, 8928-8937. [CrossRef]

15. Liu, Y.; Nair, M.G. Curcuma longa and Curcuma mangga leaves exhibit functional food property. Food Chem. 2012, 135, 634-640. [CrossRef]

16. Park, B.-S.; Kim, J.-R.; Lee, S.-E.; Kim, K.S.; Takeoka, G.R.; Ahn, Y.-J.; Kim, J.-H. Selective Growth-Inhibiting Effects of Compounds Identified in Tabebuia impetiginosa Inner Bark on Human Intestinal Bacteria. J. Agric. Food Chem. 2005, 53, 1152-1157. [CrossRef]

17. Changtam, C.; de Koning, H.P.; Ibrahim, H.; Sajid, M.S.; Gould, M.K.; Suksamrarn, A. Curcuminoid analogs with potent activity against Trypanosoma and Leishmania species. Eur. J. Med. Chem. 2010, 45, 941-956. [CrossRef]

18. Ishida, J.; Ohtsu, H.; Tachibana, Y.; Nakanishi, Y.; Bastow, K.F.; Nagai, M.; Wang, H.-K.; Itokawa, H.; Lee, K.-H. Antitumor Agents. Part 214: Synthesis and Evaluation of Curcumin Analogues as Cytotoxic Agents. Bioorganic Med. Chem. 2002, 10, $3481-3487$. [CrossRef]

19. Tocharus, J.; Jamsuwan, S.; Tocharus, C.; Changtam, C.; Suksamrarn, A. Curcuminoid analogs inhibit nitric oxide production from LPS-activated microglial cells. J. Nat. Med. 2012, 66, 400-405. [CrossRef] [PubMed]

20. Lee, S.-L.; Huang, W.-J.; Lin, W.W.; Lee, S.-S.; Chen, C.-H. Preparation and anti-inflammatory activities of diarylheptanoid and diarylheptylamine analogs. Bioorganic Med. Chem. 2005, 13, 6175-6181. [CrossRef] [PubMed]

21. Gomes Dde, C.; Alegrio, L.V.; de Lima, M.E.; Leon, L.L.; Araujo, C.A. Synthetic derivatives of curcumin and their activity against Leishmania amazonensis. Arzneim. Forsch. 2002, 52, 120-124. [CrossRef]

22. Dormán, G.; Kocsis, L.; Jones, R.; Darvas, F. A benchtop continuous flow reactor: A solution to the hazards posed by gas cylinder based hydrogenation. J. Chem. Health Saf. 2013, 20, 3-8. [CrossRef]

23. Wagner, C.E.; Marshall, P.A.; Cahill, T.M.; Mohamed, Z. Visually Following the Hydrogenation of Curcumin to Tetrahydrocurcumin in a Natural Product Experiment That Enhances Student Understanding of NMR Spectroscopy. J. Chem. Educ. 2013, 90, 930-933. [CrossRef]

24. Batie, S.; Lee, J.H.; Jama, R.A.; Browder, D.O.; Montano, L.A.; Huynh, C.C.; Marcus, L.M.; Tsosie, D.G.; Mohammed, Z.; Trang, V.; et al. Synthesis and biological evaluation of halogenated curcumin analogs as potential nuclear receptor selective agonists. Bioorganic Med. Chem. 2013, 21, 693-702. [CrossRef] [PubMed]

25. Somparn, P.; Phisalaphong, C.; Nakornchai, S.; Unchern, S.; Morales, N.P. Comparative Antioxidant Activities of Curcumin and Its Demethoxy and Hydrogenated Derivatives. Biol. Pharm. Bull. 2007, 30, 74-78. [CrossRef] [PubMed] 
26. Murakami, Y.; Ishii, H.; Takada, N.; Tanaka, S.; Machino, M.; Ito, S.; Fujisawa, S. Comparative anti-inflammatory activities of curcumin and tetrahydrocurcumin based on the phenolic $\mathrm{O}-\mathrm{H}$ bond dissociation enthalpy, ionization potential and quantum chemical descriptor. Anticancer Res. 2008, 28, 699-707. [PubMed]

27. Yoysungnoen, B.; Bhattarakosol, P.; Changtam, C.; Patumraj, S. Effects of Tetrahydrocurcumin on Tumor Growth and Cellular Signaling in Cervical Cancer Xenografts in Nude Mice. Biomed. Res. Int. 2016, 2016, 1781208. [CrossRef]

28. Ali, M.S.; Mudagal, M.P.; Goli, D. Cardioprotective effect of tetrahydrocurcumin and rutin on lipid peroxides and antioxidants in experimentally induced myocardial infarction in rats. Die Pharm. 2009, 64, 132-136.

29. Huang, Y.; Cao, S.; Zhang, Q.; Zhang, H.; Fan, Y.; Qiu, F.; Kang, N. Biological and pharmacological effects of hexahydrocurcumin, a metabolite of curcumin. Arch. Biochem. Biophys. 2018, 646, 31-37. [CrossRef]

30. Luo, D.-D.; Chen, J.-F.; Liu, J.-J.; Xie, J.-H.; Zhang, Z.-B.; Gu, J.-Y.; Zhuo, J.-Y.; Huang, S.; Su, Z.-R.; Sun, Z.-H. Tetrahydrocurcumin and octahydrocurcumin, the primary and final hydrogenated metabolites of curcumin, possess superior hepatic-protective effect against acetaminophen-induced liver injury: Role of CYP2E1 and Keap1-Nrf2 pathway. Food Chem. Toxicol. 2019, 123, 349-362. [CrossRef]

31. Zhang, Z.-B.; Luo, D.-D.; Xie, J.-H.; Xian, Y.-F.; Lai, Z.-Q.; Liu, Y.-H.; Liu, W.-H.; Chen, J.-N.; Lai, X.-P.; Lin, Z.-X.; et al. Curcumin's Metabolites, Tetrahydrocurcumin and Octahydrocurcumin, Possess Superior Anti-inflammatory Effects in vivo Through Suppression of TAK1-NF-kB Pathway. Front. Pharmacol. 2018, 9, 1181. [CrossRef]

32. Balogh, G.T. Physicochemical characterisation in drug discovery. Drug Discov. Today: Technol. 2018, 27, 1-2. [CrossRef]

33. Lu, C.; Li, P.; Gallegos, R.; Uttamsingh, V.; Xia, C.Q.; Miwa, G.T.; Balani, S.K.; Gan, L.S. Comparison of intrinsic clearance in liver microsomes and hepatocytes from rats and humans: Evaluation of free fraction and uptake in hepatocytes. Drug Metab. Dispos. 2006, 34, 1600-1605. [CrossRef]

34. Słoczyńska, K.; Gunia-Krzyżak, A.; Koczurkiewicz, P.; Wójcik-Pszczoła, K.; Żelaszczyk, D.; Popiół, J.; Pękala, E. Metabolic stability and its role in the discovery of new chemical entities. Acta Pharm. 2019, 69, 345-361. [CrossRef]

35. Wang, Y.-J.; Pan, M.-H.; Cheng, A.-L.; Lin, L.-I.; Ho, Y.-S.; Hsieh, C.-Y.; Lin, J.-K. Stability of curcumin in buffer solutions and characterization of its degradation products. J. Pharm. Biomed. Anal. 1997, 15, 1867-1876. [CrossRef]

36. Ireson, C.R.; Jones, D.J.; Orr, S.; Coughtrie, M.W.; Boocock, D.J.; Williams, M.L.; Farmer, P.B.; Steward, W.P.; Gescher, A.J. Metabolism of the cancer chemopreventive agent curcumin in human and rat intestine. Cancer Epidemiol. Biomark. Prev. 2002, 11, 105-111.

37. Shalaeva, M.; Caron, G.; Abramov, Y.A.; O’Connell, T.N.; Plummer, M.S.; Yalamanchi, G.; Farley, K.A.; Goetz, G.H.; Philippe, L.; Shapiro, M.J. Integrating Intramolecular Hydrogen Bonding (IMHB) Considerations in Drug Discovery Using $\Delta \log P$ As a Tool. $J$. Med. Chem. 2013, 56, 4870-4879. [CrossRef]

38. Desai, P.V.; Raub, T.J.; Blanco, M.-J. How hydrogen bonds impact P-glycoprotein transport and permeability. Bioorganic Med. Chem. Lett. 2012, 22, 6540-6548. [CrossRef] [PubMed]

39. Alex, A.; Millan, D.S.; Perez, M.; Wakenhut, F.; Whitlock, G.A. Intramolecular hydrogen bonding to improve membrane permeability and absorption in beyond rule of five chemical space. MedChemComm 2011, 2, 669-674. [CrossRef]

40. Liang, N.; Kitts, D.D. Antioxidant Property of Coffee Components: Assessment of Methods that Define Mechanisms of Action. Molecules 2014, 19, 19180-19208. [CrossRef] [PubMed]

41. Hunyadi, A. The mechanism(s) of action of antioxidants: From scavenging reactive oxygen/nitrogen species to redox signaling and the generation of bioactive secondary metabolites. Med. Res. Rev. 2019, 39, 2505-2533. [CrossRef] [PubMed]

42. ACD/Labs Percepta, version: v2020 Build 3382. Available online: https://www.acdlabs.com/products/percepta/ (accessed on 18 June 2020).

43. Wager, T.T.; Hou, X.; Verhoest, P.R.; Villalobos, A. Central Nervous System Multiparameter Optimization Desirability: Application in Drug Discovery. ACS Chem. Neurosci. 2016, 7, 767-775. [CrossRef] [PubMed]

44. Hopkins, A.L.; Keserü, G.M.; Leeson, P.D.; Rees, D.C.; Reynolds, C.H. The role of ligand efficiency metrics in drug discovery. Nat. Rev. Drug Discov. 2014, 13, 105-121. [CrossRef] [PubMed]

45. Jayaprakasha, G.K.; Nagana Gowda, G.A.; Marquez, S.; Patil, B.S. Rapid separation and quantitation of curcuminoids combining pseudo two-dimensional liquid flash chromatography and NMR spectroscopy. J. Chromatogr. B 2013, 937, 25-32. [CrossRef]

46. Pethő, B.; Zwillinger, M.; Csenki, J.T.; Káncz, A.E.; Krámos, B.; Müller, J.; Balogh, G.T.; Novák, Z. Palladium-Catalyzed 2,2,2Trifluoroethoxylation of Aromatic and Heteroaromatic Chlorides Utilizing Borate Salt and the Synthesis of a Trifluoro Analogue of Sildenafil. Chemistry 2017, 23, 15628-15632. [CrossRef]

47. Müller, J.; Esső, K.; Dargó, G.; Könczöl, Á.; Balogh, G.T. Tuning the predictive capacity of the PAMPA-BBB model. Eur. J. Pharm. Sci. 2015, 79, 53-60. [CrossRef]

48. Fukumoto, L.R.; Mazza, G. Assessing Antioxidant and Prooxidant Activities of Phenolic Compounds. J. Agric. Food Chem. 2000, 48, 3597-3604. [CrossRef] [PubMed]

49. Lúcio, M.; Ferreira, H.; Lima, J.L.F.C.; Reis, S. Use of liposomes to evaluate the role of membrane interactions on antioxidant activity. Anal. Chim. Acta 2007, 597, 163-170. [CrossRef] [PubMed] 